\title{
EDUCAÇÃO FINANCEIRA DOS PAIS E O IMPACTO NA VIDA DOS
} FILHOS

\author{
PARENTS' FINANCIAL EDUCATION AND THE IMPACT ON CHILDREN'S LIVES
}

Diego Oliveira Sales ${ }^{1}$

${ }^{1}$ Pós-Graduando em Docência em Administração, Especialista MBA em Gestão Financeira e Controladoria, Especialista em Educação Financeira com Neurociência, graduando em Ciências Contábeis e Graduado em Administração e Ciênias Econômicas, Pesquisador em Educação Financeira e Escritor.

admdiegosales@gmail.com
SALES, D. O. Educação financeira dos pais e o impacto na vida dos filhos. Akrópolis, Umuarama, v. 29, n. 2, p. 139-143, jul./ dez. 2021.

\section{DoI: 10.25110/akropolis.v29i2.8311}

Resumo: Esta pesquisa foi desenvolvida com objetivo de identificar e descrever os impactos percebidos na vida de crianças de uma família educada financeiramente. Esta pesquisa foi necessária em vista as fortes mudanças financeiras, econômicas e estratégias de consumo às quais as famílias estão sendo expostas. Para formar cidadãos adultos financeiramente conscientes e responsáveis, a educação financeira deve ser compartilhada, praticada e que faça parte do cotidiano das crianças. Para a execução deste trabalho, foi realizada uma pesquisa qualitativa, com base na entrevista semiestruturada aplicada a uma família com crianças, com idades entre 3 e 12 anos, escolhidas aleatoriamente dentro dos objetivos da pesquisa. De acordo com o estudo, os pais aplicam os mesmos métodos de educação financeira de que quando criança receberam, valorizam o dinheiro oriundo de trabalho, ganhos atrelados a cooperação nas atividades do lar e desempenho acadêmico. Recentemente as crianças começaram a alocar os ganhos para a realização de objetivos e sonhos.

Palavras-chave: Educação Financeira; Crianças; Sonhos.

ABSTRACT: This research was developed with the purpose of identifying and describing the perceived impacts on the lives of children from a financially educated family. This research was necessary in view of the strong financial, economic and consumption strategy changes to which families are currently being exposed. In order to educate adults to be financially conscious and responsible, financial education must be shared, practiced and be a part of children's daily lives. This work used a qualitative survey based on a semi-structured interview applied to a family with children aged between 3 and 12 years, chosen at random within the research objectives. According to the study, parents apply the same financial education methods they received as a child, valuing money from work, gains linked to cooperation in home chores and academic performance. Children have recently started to take advantage of the gains to achieve their goals and dreams.

KeYwoRDS: Financial education; Children; Dreams. 


\section{INTRODUÇÃO}

É recente e notável o número de pesquisas realizadas em busca de respostas para as questões ligadas à educação financeira infantil. Estes números devem-se a forte preocupação de profissionais educadores quanto ao futuro financeiro destas crianças. Preocupações reais e necessárias diante de fortes mudanças e influências mercadológicas que estimulam um comportamento de consumo inconsciente e a falta de perspectiva quanto ao futuro financeiro sustentável dessas crianças.

Falar em educação financeira em nossos dias não é mais tabu e muito menos assunto, unicamente, para adultos, pois tanto adultos quanto crianças são frequentemente influenciados pela força mercadológica do consumo e recebedores de recursos financeiros, seja por meio de mesada ou remuneração. Consumir se faz necessário para a subsistência do ser humano, porém alguns cuidados precisam ser levados em conta. Cuidados com o direcionamento dos recursos, com a quantidade e com motivo gerador do gasto deve ser uma responsabilidade tanto de adultos, quanto de crianças.

Dificilmente nós adultos fomos ensinados a lidar com o dinheiro quando criança e devido esta lacuna, muito do nosso comportamento financeiro traz uma bagagem projetada na vida financeira de nossos pais e, infelizmente, muitos deles tiveram uma relação bastante conturbada com o dinheiro.

Essa má relação com o dinheiro, se deve ao fato de que não fomos ensinados quando crianças a trabalhar com o dinheiro, não fomos ensinados a comprar com consciência, a economizar, a poupar e muito menos a pensar em um futuro sustentável financeiramente.

Olhando para a realidade financeira das pessoas é possível perceber que a falta de familiaridade com o dinheiro quando criança trouxe grandes problemas para a sociedade em geral. Os principais problemas enfrentados hoje pelos indivíduos, são com endividamento e inadimplência, consumo inconsciente e falta de prioridade e responsabilidade com o futuro financeiro sustentável.

Diante da preocupação com a má relação das famílias com o dinheiro, e quando mencionase famílias, engloba -se principalmente as crianças, este artigo se propõe a identificar os impactos percebidos na vida de crianças cujos pais são educados financeiramente.

\section{FUNDAMENTAÇÃO TEÓRICA}

Em meio a inúmeros materiais publicados e direcionados para públicos diferentes, o assunto educação financeira, ainda é delicado, mas tem ganhado força nos últimos anos, nos lares, nas empresas e principalmente nas escolas e universidades. Constituindo-se diferentes o púbico para o qual estes estudos e materiais são direcionados, compreender o conceito de educação financeira é a premissa básica e essencial para iniciar uma reeducação no que diz respeito ao comportamento financeiro dos indivíduos.

Vimos ainda que o entendimento em relação a educação financeira está muito associado a terminologia "finanças pessoais", o que atualmente tem sido classificado por diversos estudiosos como divergentes, a primeira por se tratar de comportamento e a segunda de gestão de recursos pessoais com base em cálculos matemáticos aplicados, uso de planilhas eletrônicas, controle, gestão de risco e investimentos.

Para Domingos (2014) "à educação financeira e as finanças pessoais diferem em seus objetivos e amplitude, sendo a primeira baseada em mudanças de hábitos e comportamentos direcionados para a realização de sonhos em família e a segunda como técnicas de gestão de recursos de indivíduos direcionados apenas para controle rigoroso da renda e dos gastos pessoais". É claro que as finanças pessoais trazem grandes benefícios para a vida financeira dos seus usuários, porém quando usada somente como conhecimento voltado para controle de recursos se torna apenas uma ciência capaz de gerar frustrações e desânimo. Quando o indivíduo passa a controlar seus recursos sem o objetivo de realização de sonhos e sem a consciência da mudança de hábitos e costumes financeiros, a propensão ao desânimo e ao insucesso financeiro é muito grande.

Domingos (2014) "menciona também que a facilidade em gerir os recursos não quer dizer que o indivíduo seja educado financeiramente, pois pode apresentar domínio ao fazer cálculos financeiros e mexer com planilhas, porém não havendo mudanças nos hábitos e costumes financeiros destas pessoas".

Ao contrário das finanças pessoais, a educação financeira como já mencionado acima 
está intimamente ligada com as mudanças de hábitos e comportamentos financeiros e deve ser adotada não só por um indivíduo, mas por toda a família. Assim, corrobora Silva et al. (2018), "ao dizer que a educação financeira deve passar pela base familiar para que todos participem". Para Leite, Rejane e Lemes (2010), "o assunto deve ser levado a conhecimento de todos os membros da família para que trabalhem juntos como equipe".

A educação financeira é o meio pelo qual contribui para a mudança de hábitos e comportamentos financeiros dos indivíduos, tornando-os cidadãos responsáveis. (MARONESE; CARVALHO, 2016). É também o processo pelo qual a sociedade aprende sobre os conceitos e aplicações financeiras, buscando uma melhor qualidade de vida, tomando decisões que impactarão diretamente o bem-estar da família (SILVA; NOGUEIRA, 2018).

Diante dos conceitos apresentados acima, podemos entender a importância da inclusão da educação financeira no dia a dia das famílias, pois além de introduzir os conceitos e aplicações financeiras, estimulam os indivíduos a mudanças de hábitos e costumes que os impedem de terem o sucesso financeiro.

Não podemos achar que a educação financeira seja assunto apenas para os adultos. De maneira nenhuma, pois são as crianças o futuro da nossa sociedade e delas dependerá o futuro financeiro responsável, consciente e sustentável. Assim, a educação financeira deve de maneira clara e didática ser compartilhada com as crianças, pois visa a auxiliar crianças, adolescentes, jovens e adultos na administração dos recursos e em suas decisões de poupar e investir de olho em um futuro responsável, (DORNELA et al., 2014).

Se diante das fortes estratégias de consumo direcionada as crianças não forem apresentadas informações de conscientização quanto ao uso dos recursos, poderão de acordo com VENTURA JUNIOR et al. (2017) se tornar jovens e adultos com sérios problemas financeiros e até pessoais.

Como se trata de crianças, a educação financeira deve ser inserida no lar por meio de pais responsáveis, e que sejam além de teóricos, praticantes dos ensinos da educação financeira. São os pais as primeiras referências dos filhos na formação dos hábitos e comportamentos financeiros, o que é uma grande responsabilidade, pois deles dependerão as bases para decidirem quanto a maneira de lidarem com os recursos quando se tornarem jovens e adultos.

Estudos da neurociência mostram que as crianças veem o mundo de forma diferente de nós adultos e que os primeiros anos de vida da criança são decisivos para a formação do comportamento financeiro. De acordo com Domingos (2017), a relação dos pais com o dinheiro pode ser tanto um risco quanto uma oportunidade. Isso dependerá da maneira como os pais se relacionam com o dinheiro diante dos filhos. As crianças perceberão se o comportamento financeiro dos pais é saudável ou não pela maneira como lidam com ele. Se vivem endividados, gastando de forma inconsciente, estressados e sempre reclamando da vida financeira, passarão as crianças a ideia de que aquilo é correto. Ao contrário se vivenciarem consciência, tranquilidade, planejamento e responsabilidade com o dinheiro aprenderão o que é correto e desenvolverão um comportamento saudável.

Ao serem ensinadas desde pequenas sobre educação financeira, obterão vantagens e benefícios que o seguirão por toda a vida e os farão pessoas de grande sucesso pessoal e profissional. (DOMINGOS, 2017).

Para se ensinar a criança, deve-se primeiramente deixar claro o que é educação financeira e sua importância (MENEGUETTI, et al., 2014). E a partir desta compreensão usar métodos que possam despertar nas crianças o interesse pelas atividades que tenham como único objetivo, educá-los financeiramente. Muitas estratégias e atividades estão à disposição dos pais e crianças por meio de livros, revistas, desenhos e jogos, porem devem ser sempre inseridos na vida da criança acompanhada do bom exemplo dos pais.

A disposição estão os livros, jogos, cofrinhos, mesadas etc. estratégias que são excelentes ferramentas para o ensino. Desses instrumentos, a mesada e a utilização de cofrinhos são os mais comuns entre crianças e que atrelado a ela está um forte poder de ensino. Para Domingos (2015), a mesada não é apenas o recebimento de dinheiro, mas de ganhos por meio de consumo consciente, reaproveitamento de materiais, trocas, responsabilidade social e todas estas formas trazem em si ganhos que irão proporcionar muitos aprendizados as crianças. Com este método de ensino, as crianças aprenderão a economizar, fazer trocas, reaproveitar materiais, empreender e fazer bom uso dos recursos recebidos, direcionando os ganhos para a realização dos sonhos e objetivos, 
o que é segundo Domingos (2015), o principal objetivo da educação financeira.

\section{METODOLOGIA}

Para a realização deste artigo, tornou-se primeiramente necessário a utilização de materiais bibliográficos como livros, artigos, monografias e dissertações para sua fundamentação, partindo da premissa de que a informação bibliográfica, como afirma Santos, Asoo e Carvalho (2016) "traz grande vantagem por reunir diversos títulos do tema proposto disponíveis e fundamentados para a elaboração do trabalho científico".

Após a fundamentação do presente artigo, foi convidado a participar de uma entrevista, uma família com filhos com idades entre 3 e 12 anos que no seu dia a dia coloca em prática os conceitos da educação financeira. Esta escolha foi feita de forma aleatória diante da disponibilidade dos participantes dentro das características do estudo. Após a escolha da família, foi realizada uma visita para que por meio de entrevista, técnica em que o pesquisador diante do pesquisado faz perguntas a fim de obter dados para que interessam a pesquisa (GIL; 2008). Para esta pesquisa adotou o modelo de entrevista semiestruturada, que segundo Gil (2008), permite o investigado a ficar à vontade para falar, porém dentro de questões já estruturadas para evitar que haja desvio do foco da pesquisa.

\section{DISCUSSÃO E RESULTADOS}

FAMÍLIA

Quantidade de Filhos: 2 Filhos

Sexo do Filhos: Masculino

Idade dos filhos: $\mathrm{P}-9$ anos e $\mathrm{F}-7$ anos

A entrevista ocorreu com toda a família reunida, pais e filhos. Ao serem questionados se foram (os pais) educados financeiramente, onde e por quem, ambos mencionaram que foram educados em casa pelos próprios pais. Mesmo os pais sendo criados por famílias diferentes, em contextos diferentes, os métodos utilizados para educá-los financeiramente foram semelhantes. O método utilizado para educá-los em relação ao dinheiro foi o trabalho. A partir dos 6 e 7 anos de idades, ambos foram inseridos em atividades domésticas e laborais simples, porém constantes e remuneradas. Eram colocados a auxiliar os pais em casa nas atividades domésticas e no ambiente de trabalho e em contrapartida recebiam uma quantia. Por meio da remuneração que recebiam, eram orientados quanto a forma de gastar e economizar, sendo que deveriam gastar somente o que tinham disponíveis. O método de mesada como hoje é conhecido e apropriado não fazia parte da realidade destes indivíduos.

Com a utilização dos métodos utilizados pelos pais destes indivíduos, no caso o trabalho e o salário, dizem terem aprendido a dar muito valor ao trabalho, como fonte de renda e, principalmente, ao dinheiro recebido como troca pelos serviços prestados. Dando valor ao dinheiro, gastam com consciência e responsabilidade.

Percebeu-se na entrevista que os métodos de educação utilizados hoje com os filhos têm forte relação com os métodos que foram utilizados para educarem os pais financeiramente. Os filhos são submetidos a atividades domésticas simples, a bom desempenho acadêmico e leitura e em contrapartida recebem de forma aleatória e não sistemática pequenas quantias em troca destas atividades.

Como objetivo da pesquisa, buscou-se identificar junto aos pais e filhos os impactos produzidos com a aplicação de conceitos e métodos de educação financeira. Foi identificada forte relação ao que os pais aprenderam e hoje ensinam que os filhos dão muito valor ao dinheiro, já que conseguem identificar quando o gasto é necessário ou não; a relação custo e qualidade; e ultimamente os filhos têm atrelado os ganhos a realização de sonhos e objetivos. Logo, consoante a proposta da educação financeira conforme apresenta o educador financeiro Reinaldo Domingos.

Outra questão importante é que habitualmente a família, pais e os filhos direcionam $10 \%$ de todos os ganhos como dízimo por serem uma família cristã.

\section{CONCLUSÃO}

Diante das diversas formas de ensino da educação financeira disponíveis no mercado, os responsáveis da família estudada reproduzem na vida dos filhos os mesmos métodos que foram utilizados para educá-los quando crianças. Trabalho, auxílio nas atividades domésticas, bom desempenho acadêmico são os critérios para 
a entrega de quantias para os filhos. Métodos como mesadas ou uso de cofres não fazem parte do dia a dia dessas crianças. Conforme os pais e as próprias crianças mencionaram, valorizar o dinheiro, fazer relação custo versus benefício já faz parte de seu repertório de conhecimento. Outra questão importante é o da autonomia e hábito que desenvolveram ao praticarem a devolução de $10 \%$ de tudo que ganham como dízimo por se tratar de uma família cristã.

O educador e terapeuta financeiro Reinaldo Domingos traz de maneira didática e objetiva a educação financeira como meio para a realização de sonhos e mesmo os filhos da família estudada não terem tido acesso a estes conceitos, estão atrelando os ganhos a realização de objetivos e sonhos.

Para melhores resultados e abrangência sugere-se pesquisa com maior número de famílias.

\section{REFERÊNCIAS}

Domingos, Reinaldo. CADERNO DA FAMÍLIA: Coleção dos Sonhos. - São Paulo: Editora DSOP, 2017.

\section{DOMINGOS, Reinaldo. EDUCAÇÃO}

FINANCEIRA E FINANÇAS: Qual a diferença? DSOP educação financeira, São Paulo, 15 de abr. de 2014. Disponível em: https://www.dsop.com.br/ artigos/2014/04/educacao-financeira-e-financaspessoais-qual-diferenca/. Acesso em: 07 Nov. de 2019.

DOMINGOS, Reinaldo. MESADA NÃO É SÓ DINHEIRO: Conheça os 8 tipos e construa um novo futuro. 1. Ed. - São Paulo: DSOP, 2015.

DORNELAS, Junia F. et al. EDUCAÇÃO

FINANCEIRA: Aprendendo a lidar com o dinheiro. RAI. RUM., VOL. 02 NN$^{\circ}$ 01, 91 - 155, RIO DE JANEIRO, JUN., 2014.

GIL, Antônio Carlos. MÉTOdos E TÉCNICAS DE PESQUISA SOCIAL. - 6. ed. - São Paulo: Atlas, 2008.

VENTURA JUNIOR, R. et al. EDUCAÇÃO FINANCEIRA: Brincando com o dinheiro. Revista Guarujá, v. 5, n. 8, dez. 2017.

LEITE, Correia L.; REJANE, Aparecida; LEMES, Palhares. EDUCAÇÃO FINANCEIRA. Iniciação científica discente, vol. 13, n. 21, Ano 2010.

MARONESE, Maria C. M. B.; CARVALHO, Túlio O. EDUCAÇÃO FINANCEIRA: UMA NECESSIDADE PARA OS JOVENS CONSUMIDORES. OS

desafios da escola pública paranaense na perspectiva do professor PDE, ISBN 978-85-8015093-3 cadernos PDE, v. 1, 2016.

MENEGHETTI NETO, Alfredo. et al. EDUCAÇÃO FINANCEIRA; Porto Alegre: EDIPUCRS, 2014.

SANTOS, Bruna N.; ASOO, Rafael S.; CARVALHO, Carolina G. EDUCAÇÃO

FINANCEIRA INFANTIL: A CONSTRUÇÃO DE CIDADÃOS CONSCIENTES. Org. Soc., Iturama (MG), v. 5, n. 4, p. 116-126, jul./dez. 2016.

SILVA, Ana L. Paz. et al. Finanças pessoais: uma análise de educação financeira de jovens estudantes do IFPB. Revista Principia, n. 41, João Pessoa, 2018.

SILVA, Vanessa A. P. S.; NOGUEIRA, Renan F. G. Educação Financeira Ligada à Vida Profissional e Corporativa. Revista H-Tec Humanidades e Tecnologia. Edição Especial EIC 2018, v. 2, n. 1, p. 6-166, jan./jun., 2018.

\section{LA EDUCACIÓN FINANCIERA DE LOS PADRES Y EL IMPACTO EN LA VIDA DE LOS HIJOS}

RESUMEN: Esta investigación se desarrolló con el objetivo de identificar y describir los impactos percibidos en la vida de los niños de una familia con educación financiera. Investigación necesaria en vista de los fuertes cambios financieros, económicos y las estrategias de consumo a los que están expuestas las familias. Para educar a ciudadanos adultos responsables y conscientes, la educación financiera debe ser compartida, practicada y hacer parte de la vida diaria de los niños. Para la ejecución de este trabajo se realizó una investigación cualitativa, a partir de entrevista semiestructurada aplicada a una familia con hijos, de entre 3 y 12 años, elegidos al azar dentro de los objetivos de la pesquisa. Según el estudio, los padres aplican los mismos métodos de educación financiera que recibieron de niños, valoran el dinero del trabajo, las ganancias vinculadas a la cooperación en las actividades del hogar y el rendimiento académico. Los niños han comenzado recientemente a aprovechar los logros para la realización de objetivos y sueños.

Palabras Clave: Educación financiera; Niños; Sueños. 